\title{
Polycystic kidney disease with unilateral ventriculomegaly: a case report
}

\author{
Mohammed Khairy Ali, MBBCh, MSc, ${ }^{1}$ Ahmed Y Abdelbadee, MBBCh, MSc, ${ }^{1}$ Sherif A \\ Shazly, MBBCh, MSc, ${ }^{1}$ Ahmed M. Abbas, MBBCh, MSc ${ }^{1}$
}

Keywords: polycystic kidney disease, unilateral ventriculomegaly, oligohydramnios

\begin{abstract}
Polycystic Kidney Disease (PKD) is an autosomal recessive disease with an incidence of about 1 in 30,000 births. It characterized by multiple cysts which filled by fluid that can ultimately impede kidney function leading to degeneration of renal tissue and renal failure. Oligo or anhydramnios is frequently present but not invariably so, suggesting that some degree of renal function is retained in some PKD cases. We present a 30 year old woman, gravida 5, para 4, at 22 weeks of gestation with ultrasound findings of autosomal recessive PKD (ARKPD), unilateral ventriculomegaly and marked oligohydramnios. Ventriculomegaly is a brain condition that occurs when the width of the atrium of the lateral ventricle is greater than 10 $\mathrm{mm}$ and occurs in 0.3-1.5 births per 1000. The association between autosomal recessive PKD and unilateral ventriculomegaly is not well understood and needs further evaluation.

${ }^{1}$ Woman's Health Hospital, Assiut University, Assiut, Egypt.
\end{abstract}

\section{Introduction}

Polycystic kidney disease (PKD) is a bilateral anomaly characterized by fusiform cystic dilatations of the collecting ducts. It is an autosomal recessive disease with an incidence of about 1 in 30,000 births. ${ }^{1}$ The kidneys appear spongy with no clear separation between the cortex and medulla. The cut surface demonstrates cortical extension of fusiform or cylindrical spaces arranged radially throughout the renal parenchyma from the medulla to the cortex. Autosomal recessive PKD may be associated with other malformations like cystic fibrosis of the liver, pulmonary hypoplasia, and the Potter phenotype, with the latter two linked to severe oligohydramnios. ${ }^{2}$

Ventriculomegaly may be the consequence of a variety of conditions that can result in a dilatation of the cerebral ventricular system. The incidence of congenital enlargement of the cerebral ventricles ranges between 0.3 and 1.5 per 1000 births, depending on the study. However, this may be an underestimate, as most available surveys are based upon clinical data, and enlarged ventricles are presumably asymptomatic at birth in many cases.

Please cite this paper as: Ali MK, Abdelbadee AY, Shazly SA, Abbas MA. Polycystic kidney disease with unilateral ventriculomegaly: a case report. Proc Obstet Gynecol. 2013;3(2):Article 12 [4 p.]. Available from: http://ir.uiowa.edu/pog/. Free full text article.

Corresponding author: Mohammed Khairy Ali, Woman's Health Hospital, Assiut University, Assiut, Egypt. Business telephone number: +208824621. Cellular phone number: +2 01005537951. Postal code: 71111. E-mail: mohammedelkosy@yahoo.com

This is an Open Access article distributed under the terms of the Creative Commons Attribution 3.0 Unported License (http://creativecommons.org/licenses/by/3.0), which permits unrestricted use, distribution, and reproduction in any medium, provided the original work is properly cited. 
The rate of association with other cerebral anomalies (holoprosencephaly, corpus callosum agenesis, and DandyWalker malformation) and extracerebral anomalies (myelomeningocele) ranges from $45 \%$ to $80 \%{ }^{4}$

\section{Case presentation:}

The patient is a 30 year old woman, gravida 5, para 4, with four living children. Her previous pregnancies were uncomplicated and her children did not have any structural anomalies. Her husband is her cousin. At 22 weeks of gestation, she presented to the Women's Health Hospital at Assiut University for antenatal care. The gestational age was confirmed by ultrasound and was consistent with her last menstrual period. The ultrasound findings were as follows: 1. polycystic kidney disease (Figure 1); 2. unilateral ventriculomegaly with atrial width of 1.38 $\mathrm{cm}$ (Figure 2); and 3. marked oligohydramnios.

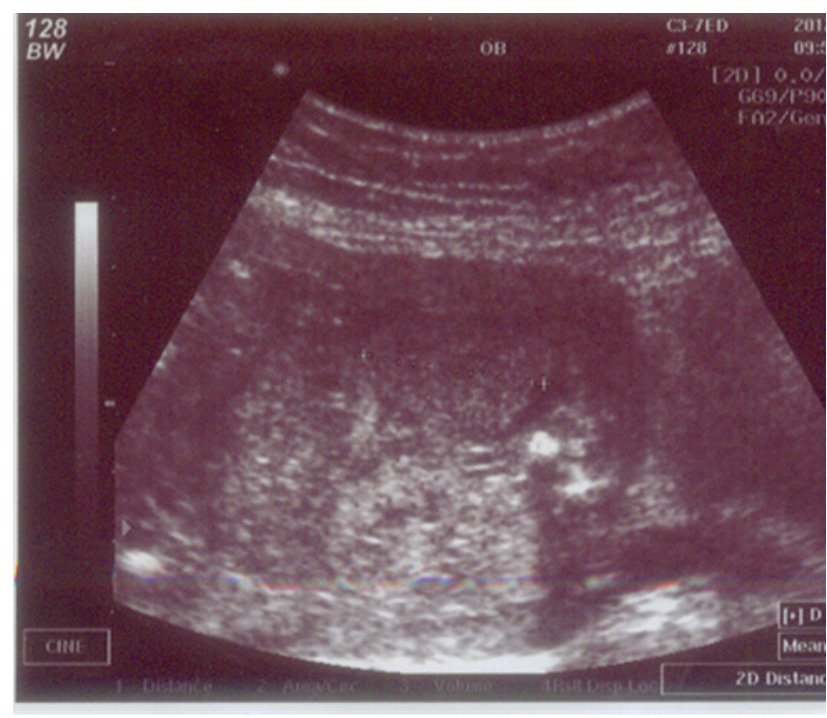

Figure 1: Coronal view of ultrasound shows bilateral polycystic kidney
We explained to the patient the nature and severity of the anomaly with its possible poor outcome. Despite the advice of the medical team for termination of the pregnancy, the patient preferred continuation of pregnancy and follow up after 2 weeks. Two weeks later on a regular $O B$ visit, the fetus was found to have no heart pulsation. Prostaglandin induction of abortion was performed.

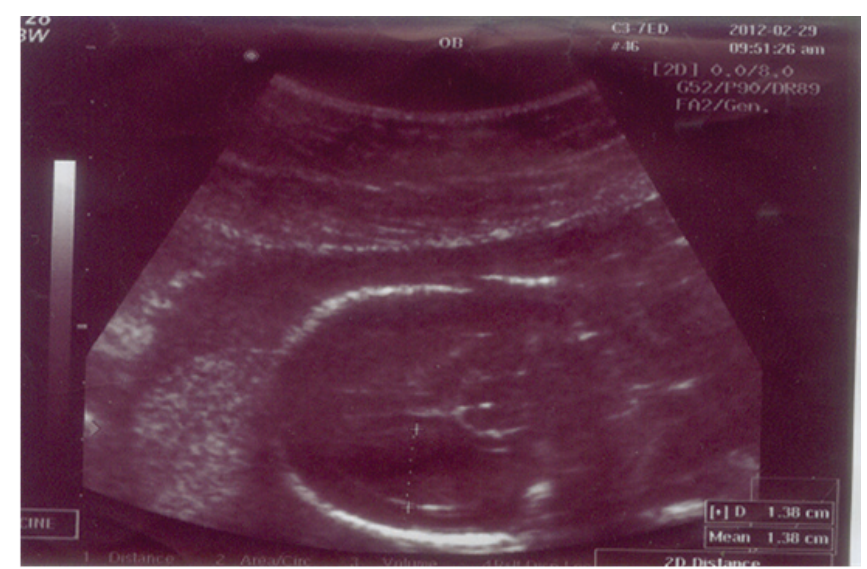

Figure 2: sagittal view of fetal head shows unilateral ventriculomegaly

\section{Discussion:}

Ciliary dysfunction is a common factor responsible for both isolated and syndromic kidney cystic disease. ${ }^{5}$ Cilia are small microtubular structures. There are two types of cilia: motile or immotile. Many years ago, motile cilia were studied by the scientists who study the dynamics and physiological importance of their motility. Dysfunction of the cilium is responsible for multiple human genetic disorders which are called the ciliopathies. Many abnormalities have been associated with cilia dysfunction, like neural tube closure defects, skeletal defects, polycystic kidney disease, and liver disease. Behavioral and cognitive 
defects are also associated with ciliopathies. Polycystic kidney disease (PKD) is a genetic disease characterized by the presence of multiple small cysts in the kidneys that are filled with fluid. These cysts may result in enlargement of the kidneys, which leads to decreased kidney function and finally kidney failure. However, these cysts can also affect other organs like the liver, pancreas, and large blood vessels in the brain and heart. $^{6}$ The presence of multiple cysts and poor prognosis can help doctors to differentiate between PKD and simple cysts that often are harmless and develop later. Autosomal recessive PKD is a rare inherited form of the disease; it can occur not only early in life but also in utero. ${ }^{7}$

The term ventriculomegaly means that the atrial width is $>10 \mathrm{~mm}$. It has two types: the first is unilateral ventriculomegaly and the second is bilateral ventriculomegaly. It can be also described as a separation of more than $3 \mathrm{~mm}$ of the choroid plexus from the medial wall of the lateral ventricle. However; hydrocephalus means that the atrial diameter is more than $15 \mathrm{~mm}^{8}$ There are many fetal renal abnormalities, including bilateral renal agenesis, unilateral renal agenesis with no functioning other kidney, bilateral polycystic kidney and out flow renal anomalies. All these anomalies cause oligohydramnios due to the decrease in production of amniotic fluid. ${ }^{9}$ An enlarged kidney can be present in many syndromes. In Bardet-Biedl syndrome, there is ARPKD with polydactyly and a normal amount of amniotic fluid. In Meckel-Gruber syndrome, there is PCK with CNS anomalies and polydactyly. ${ }^{10}$
In Beckwith-Wiedemann syndrome there is polycystic kidney, macroglossia, omphalocele, and hemihypertrophy. ${ }^{11}$

In this report, we represent a case of 22 weeks pregnancy with polycystic kidney disease, unilateral ventriculomegaly and marked oligohydramnios. However, there are many interesting points to discuss in this case. First: to our knowledge, there were no reported cases of pregnancy with fetuses that had Polycystic Kidney Disease and unilateral ventriculomegaly. Second: there is an association between renal cystic diseases and central nervous system malformations; this may be due to the loss of ciliary function which is an interesting finding that needs further evaluation and search. However, there may be other anomalies in this baby that can't be detected due to marked oligohydramnios.

\section{Conclusion:}

In this report, we represent a rare case of a 22 weeks pregnancy with polycystic kidney disease, unilateral ventriculomegaly and marked oligohydramnios. The association between polycystic kidney disease and unilateral ventriculomegaly is an interesting finding that needs further evaluation.

\section{References}

1. Gruskin D, Kanil E, Rimoin D. Congenital disorders of the urinary tract. In: Rimoin D, Connor JM, Pyeritz RE, Korf BR, editors. Emery and Rimoin's Principles and Practice of Medical Genetics, 4th ed. Edinburgh: ChurchillLivingstone; 2002. p. 1659-743. 
2. Winyard P, Chitty L. Dysplastic and polycystic kidneys: diagnosis, associations and management. Prenat Diagn. $2001 \quad$ Nov;21(11):924-35. PubMedPMID: $\quad 11746145$. http://dx.doi.org/10.1002/pd.208

3. Garel C. Ventricular dilatation. In: Garel C, editor. MRI of the Fetal Brain: Normal Development and Cerebral Pathologies. Berlin: Springer-Verlag; 2004. p. 20116.

4. Barkovich AJ. Congenital malformations of the brain and skull. In: Pediatric Neuroimaging, 3rd ed. Philadelphia, PA: Lippincot Williams \& Wilkins; 2000. p. 251-381.

5. Sharma N, Berbari NF, Yoder BK. Ciliary dysfunction in developmental abnormalities and diseases. Curr Top Dev Biol. 2008;85:371-427. doi: 10.1016/S0070-2153(08)00813-2.

PubMed PMID: 19147012.

6. Brun M, Maugey-Laulom B, Eurin D, Didier F, Avni EF. Prenatal sonographic patterns in autosomal dominant polycystic kidney disease: a multicenter study. Ultrasound Obstet Gynecol. 2004 Jul;24(1):55-61. PubMed PMID: 15229917.

http://dx.doi.org/10.1002/uog.1098

7. Stevenson RE, Hall JG, Goodman RM editors. Human Malformations and Related Anomalies. Oxford: Oxford University Press; 1993. p. 524-531.

8. Ali MK, Shazly SA, Ali AH, Abdelbadee AY, Abbas AM. Ultrasonographic soft markers of aneuploidy in second trimester fetuses. Middle East Fertil Soc J. 2012 Dec 1;17(3):141-151.

9. Klaassen I, Neuhaus TJ, Mueller-Wiefel DE, Kemper MJ. Antenatal oligohydramnios of renal origin: longterm outcome. Nephrol Dial Transplant. 2007 Feb;22(2):432-9. Epub 2006 Oct 25. PubMed PMID: 17065192. http://dx.doi.org/10.1093/ndt/gfl591
10. Kyttälä, Mira (2006-05) (pdf). Identification of the Meckel Syndrome Gene (MKS1) Exposes a Novel Ciliopathy. National Public Health Institute, Helsinki. Retrieved 2008-0706.

11. Wangler MF, Chang AS, Moley KH, Feinberg AP, Debaun MR. Factors associated with preterm delivery in mothers of children with BeckwithWiedemann syndrome: a case cohort study from the BWS registry. Am J Med Genet A. 2005 Apr 15;134A(2):187-91. PubMed PMID: 15723285. http://dx.doi.org/10.1002/ajmg.a.30595 